\title{
Avaliações externas e trabalho docente: o que dizem os registros de professores?
}

Valéria Aparecida de Souza Siqueira*

* (Universidade Paulista - Unip, São

Paulo, São Paulo, Brasil).
Resumo: A disseminação das avaliações externas como um traço marcante das políticas educacionais tem se consolidado como um instrumento de tomada de decisões de redes públicas de ensino. Neste artigo, apresentamos resultados de pesquisa de doutorado realizada em uma escola da Rede Municipal de Ensino de São Paulo (RME/SP) que versa sobre as influências das avaliações externas sobre as concepções dos professores. Foram analisados registros de professores em diários de bordo com vistas a apreender como essas avaliações reverberam na escola. Além da forte presença das avaliações municipais nos registros sob a forma de simulados da Prova São Paulo, correções da Prova da Cidade e rodas de conversa, constatamos a falta de conhecimentos sobre as características desses exames por parte dos professores, o que dificulta a interpretação pedagógica e, consequentemente, o uso dos resultados por estes.

Palavras-chave: Avaliações externas. Uso de resultados. Diários de bordo. Prova São Paulo. 
Este artigo objetiva realçar um tema de grande relevância no contexto educacional: a presença das avaliações externas no cotidiano escolar. Presentes no país há quase 30 anos, tais avaliações começaram a ser concretizadas no final da década de 1980, quando ganharam destaque especialmente após a primeira edição do Sistema de Avaliação da Educação Básica (Saeb), em 1990, um fenômeno que vários autores (AFONSO, 1998; BARROSO, 2005; DIAS SOBRINHO, 2002) relacionam à mudança do papel do Estado na educação, um reflexo da ampla reforma educacional em curso no período. Gradualmente, assumiram relevância como instrumento de tomada de decisão de gestores de redes públicas de ensino, consideradas capazes de contribuir para a melhoria da qualidade da educação (SOUSA; OLIVEIRA, 2010; SOUSA et al., 2000). Distante de um consenso, o protagonismo assumido pelas avaliações externas veio acompanhado de críticas e desconfianças quanto ao verdadeiro papel que desempenhavam no contexto neoliberal dos anos 1990, o que provocou uma polarização no debate presente na literatura, uma parte defendendo-as como capazes de expressar toda a qualidade da educação (CASTRO, 2000, 2007) e outra parte rechaçando sua presença, concebendo-as como algo nefasto para a educação (ARELARO, 2003; DÍAZ BARRIGA, 2008; ESTEBAN, 2014).

Entre os entusiastas, podemos apontar pesquisas como Castro (2007), que salienta que tais avaliações teriam a capacidade de produzir alterações positivas nos ambientes escolares no sentido de sua crescente melhoria.

Entre as recusas, citamos trabalhos como o de Arelaro (2003), assumindo que as avaliações externas estariam gerando redução curricular e estreitamento didático de forma que os professores estariam pautando seus trabalhos por estas. Díaz Barriga (2008), por sua vez, critica o superdimensionamento dos exames alegando que a eles se confere o poder de resolução de problemas gerados em outras instâncias sociais. Concordando com essa análise, Esteban (2014, p. 465) questiona “[...] a qualidade pretendida e a proposta pedagógica em um procedimento", segundo ela, "tão redutor". Outros atribuem, ainda, um poder tal às avaliações externas, que estas serviriam como "ferramenta de controle do fazer docente”, como encontramos em Santos e Félix (2014, p. 283).

Mais moderado, Madaus (1988), expressando suas preocupações no contexto de consolidação de avaliações externas nos Estados Unidos, país no qual as avaliações externas têm uma presença de longa data e, por isso, 
mais consolidada, ponderou que testes dessa natureza podem influenciar o currículo, mas é preciso analisar que influências são essas e em que medida elas são negativas ou mesmo positivas. Stecher (2002), também estudando as avaliações externas nos EUA, salientou que o quadro no interior das escolas é complexo e que, em alguns casos, os efeitos dessas avaliações não são positivos nem negativos, elas acabam tendo um "efeito neutro", isto é, não mudam em nada o que ocorre na escola e na sala de aula. Ao questionar a excessiva confiança nos testes padronizados, o autor apontou a necessidade de pesquisas acerca dos efeitos dos testes de alto impacto e da consequente responsabilização de profissionais das escolas pelos resultados como forma de minimizar as consequências negativas e potencializar as positivas. Ainda que haja uma vasta produção acadêmica sobre os efeitos das avaliações externas nas escolas, chama a atenção o fato de que não se têm conclusões claras sobre influências e eventuais impactos dessas avaliações, seja pela ausência ou pela dificuldade de abordagem do fenômeno empiricamente, seja pela falta de um quadro conceitual consolidado.

Diante de tal polaridade sobre um assunto de grande repercussão no campo educacional, realizamos um trabalho que originou uma tese de doutorado que buscou apreender, em um contexto de forte presença das avaliações externas, quais as influências dessas nas concepções dos professores sobre avaliação.

A pesquisa foi efetivada em uma escola de Ensino Fundamental da Rede Municipal de Ensino de São Paulo (RME/SP). Importante ressaltar que se trata de uma rede que participa de diversas avaliações externas federais, municipais e internacionais. Procuramos apreender a materialização das avaliações externas no cotidiano escolar, realizando observações ao longo de três anos, além de entrevistas, questionários e análise documental. Entre os documentos examinados, encontram-se os diários de bordo ${ }^{2}$, com registros de professores dos anos iniciais do Ensino Fundamental. Os registros foram realizados ao longo do ano de 2010 por professores e alunos do Ensino Fundamental de $2^{\underline{a}}, 3^{\underline{a}}, 4^{\underline{a}}$ e $5^{\underline{a}}$ séries (Ensino Fundamental de oito anos). Buscamos identificar nesses registros marcas das avaliações externas que nos mostrassem uma das formas com que reverberam no cotidiano escolar, admitindo que registros de professores são um retrato de suas concepções e, consequentemente, de sua prática. A análise de diários de bordo desenvolvidos por professores deve-se ao fato de que representam uma importante fonte de concepções, o

2 Os diários de bordo foram um recurso utilizado pela escola no ano de 2010 para acompanhamento das atividades escolares. Foi um material incorporado à pesquisa documental, dada a quantidade de registros dos professores sobre as avaliações externas. 
que, por sua vez, se materializa nas práticas avaliativas desses professores. Zabalza (2004, p. 11) considera que os diários do professor são fonte de “[...] desenvolvimento pessoal e profissional como instrumentos de pesquisa-ação".

Assim, apresentamos neste texto resultados parciais da pesquisa de doutorado, trazendo como recorte a análise de registros de diários de bordo realizados por professores dos anos iniciais do Ensino Fundamental da escola, buscando apreender eventuais marcas das avaliações externas nesses registros que possam elucidar se estas estariam influenciando o fazer docente. Para tanto, algumas questões se fizeram necessárias para orientar o trabalho: como as avaliações externas aparecem nos registros de diários de bordo dos professores? As avaliações externas estão condicionando o trabalho docente? De que forma isso aparece nos registros?

\section{Procedimentos metodológicos}

Para a realização deste trabalho, a metodologia utilizada foi a abordagem qualitativa, que provoca os pesquisadores a esclarecer uma situação para tomada de consciência dos problemas e das condições que os geram, a fim de elaborar os meios e estratégias de resolvê-los (CHIZZOTTI, 2005). Para análise dos registros encontrados nos diários de bordo, utilizamos a análise documental e entrevistas semiestruturadas, por considerarmos esses instrumentos os mais adequados para a elucidação do problema de pesquisa. Gil (1999) define a entrevista como a técnica em que o investigador se apresenta diante do investigado e lhe formula perguntas com o objetivo de obter os dados que interessam à investigação. A entrevista proporciona uma interação entre os participantes, pois o diálogo causa flexibilidade na atuação do entrevistador, possibilitando coletar dados importantes para o desenvolvimento da pesquisa. Ludke e André (1986, p. 34) acrescentam:

\footnotetext{
A grande vantagem da entrevista sobre as outras técnicas é que ela permite a captação imediata e corrente da informação desejada, praticamente com qualquer tipo de informante e sobre os mais variados tópicos.
}

Diante do exposto, envolvemos duas professoras responsáveis pelas turmas de 2 $2^{\underline{a}}$ e $4^{\underline{a}}$ séries do Ensino Fundamental no ano de 2010 que realizaram registros nos diários analisados. Buscou-se estabelecer um diálogo com as professoras em busca de respostas aos questionamentos que originaram esta pesquisa, cientes de que se trata de um estudo de caso, evitando, portanto, generalizações, pois, segundo Chizzotti (2005), os estudos de caso visam 
explorar, desse modo, um caso singular, situado na vida real contemporânea, bem delimitado e contextualizado em tempo e lugar, para realizar uma busca circunstanciada de informações sobre um caso específico.

A análise dos registros dos diários de bordo foi uma escolha amparada nas afirmações de Porlán e Martín (1997, p. 23), que ressaltam tratar-se de um recurso metodológico que possibilita um desenvolvimento progressivo de conhecimento profissional entre teoria, planejamento e prática. Asseguram que os diários de bordo permitem ao professor refletir sobre os processos mais significativos da dinâmica em que está inserido, favorecendo, ainda, o estabelecimento de conexões significativas entre conhecimento prático e conhecimento disciplinar, o que permite tomadas de decisão mais fundamentadas.

Ainda que os diários de bordo não revelem toda a rotina da prática docente, representam um rico arcabouço de percepções diárias do professor sobre sua prática em meio a descrições e reflexões. Para além de uma demanda burocrática, tais registros guardam estreita relação com as convicções e dilemas do autor. A docência, embora reconhecida como uma profissão, não se assemelha a um trabalho comum, como mostrou Chartier (1991) - as dificuldades em exercê-lo absorvem a reflexão sobre o tema. É para questões sobre o "como fazer" que se voltam as discussões acerca do trabalho docente, questões essas que necessitam que o sujeito se abstraia das tarefas que lhe são solicitadas para interrogar-se até mesmo sobre os limites de suas ações (CHARTIER, 1991, p. 55). Nesses termos, os diários de bordo possibilitam uma apreensão do dia a dia dos professores, um ponto de partida para conhecermos um pouco mais esse universo da sala de aula. Segundo Zabalza (2004, p. 17), “[...] os diários permitem aos professores revisar elementos de seu mundo pessoal que frequentemente permanecem ocultos à sua própria percepção enquanto está envolvido nas ações cotidianas de trabalho".

Nesta pesquisa optamos pela abordagem de pesquisa-ação, concebida e realizada em estreita associação com uma ação ou com a resolução de um problema coletivo, tal como postulado por Thiollent (1986). Dialogamos ainda com Nevo (1998), que propõe uma abordagem “[...] baseada na escola, aproveitando as concepções atuais de avaliação educacional, e determinando orientações práticas para essa aplicação" (NEVO, 1998, p. 90). Sendo as concepções dos professores o objeto de nossa reflexão, é oportuno que a investigação tenha como norte os próprios relatos dos professores.

A pesquisa se desenvolveu em uma escola da Rede Municipal de Ensino 
de São Paulo (RME/SP). A escolha pela rede deveu-se ao fato de que nesta foi instituída, em 2005, por meio da Lei n. 14.063, o seu próprio Sistema de Avaliação de Aproveitamento Escolar dos Alunos - a Prova São Paulo ${ }^{3}$ -, com o objetivo de verificar o desempenho dos alunos nas séries do Ensino Fundamental e Médio, nos diferentes componentes curriculares, de modo a subsidiar tomadas de decisão em relação à formação continuada e reorientação da proposta pedagógica (SÃO PAULO, 2006).

Além disso, essa Rede tem algumas características específicas; entre elas, destacam-se suas dimensões quanto ao número de alunos e escolas, considerada uma das maiores redes públicas de ensino do país. De acordo com o Censo Escolar de 2016, 412.071 alunos estavam matriculados no Ensino Fundamental regular, em quase 600 escolas $^{4}$.

Outra justificativa para essa escolha repousa numa característica mais estritamente vinculada com a temática da pesquisa: a grande quantidade de avaliações externas a que, direta ou indiretamente, são submetidos os alunos das Escolas Municipais de Ensino Fundamental (Emef) de São Paulo. Em algumas participam efetivamente e em outras participam ou por amostragem ou pelas implicações que os resultados possuem para esta Rede. Trata-se de avaliações internacionais, nacionais e municipais. Com efeito, temos como avaliações externas diretamente vinculadas à RME/SP: Saeb/Prova Brasil, Provinha Brasil, Avaliação Nacional da Alfabetização (ANA), Prova São Paulo (PSP), Prova da Cidade e Sondagem dos níveis de alfabetização e, mais recentemente, a Prova Mais Educação ${ }^{5}$. Indiretamente, podemos mencionar também o Programa Internacional de Avaliação de Estudantes (Pisa), pois seus resultados almejam conhecer o que estariam dominando alunos egressos ou

3 Criada em 2005 e aplicada pela primeira vez em 2007, a Prova São Paulo é uma avaliação externa e de larga escala, com periodicidade anual e duração que varia de dois a três dias, de acordo com o ano da aplicação. Os componentes curriculares avaliados em 2007 a 2010 foram Língua Portuguesa e Matemática e em 2011 e 2012, incluiu-se também Ciências Naturais. Além da prova com itens de múltipla escolha, é composta por questionários de hábitos de estudo para os alunos; socioeconômico para os pais; e questionários para professores, coordenadores pedagógicos, diretores de escola e supervisores escolares. Para mais informações, visite: http://portalsme.prefeitura. sp.gov.br/default.aspx.

4 Fonte: Censo Escolar/Inep 2016.

5 A Prova Mais Educação foi instituída por meio da Portaria n. 3.611, de 29 de maio de 2015, e faz parte do Programa Mais Educação São Paulo, instituído pelo Decreto n. 54.452, de 10/10/2013 e regulamentado pela Portaria SME n. 5.930, de 15/10/2013. Trata-se de instrumento de avaliação bimestral nas unidades educacionais que mantêm o Ensino Fundamental da Rede Municipal de Ensino de São Paulo. Fonte: http://portal. sme.prefeitura.sp.gov.br/Portals/1/Files/14480.pdf. 
em conclusão do Ensino Fundamental.

A análise dos diários de bordo e a realização das entrevistas com professoras que utilizaram esse recurso ocorreram após oito meses de entrada na escola pela pesquisadora, pois a princípio outros procedimentos metodológicos foram adotados, em especial a observação de instâncias coletivas.

Ao todo, foram examinados nove diários de bordo, representantes das turmas da $1^{\underline{a}}$ série $B, 2^{\underline{a}}$ s séries $C$ e $D, 3^{\underline{a}}$ série $D, 4^{\underline{a}}$ s séries $A$ e $C$ e $5^{\underline{a}}$ s séries $A, B$ e $C$ de $2010^{6}$. Destes, conseguimos entrevistar duas professoras que ainda lecionam na escola.

O uso de diários de bordo foi uma prática da escola apenas no ano de 2010 e guardava algumas singularidades, como o fato de o registro ser feito preferencialmente por alunos, um por dia, de modo que todo o trabalho desenvolvido pela professora fosse registrado pelo aluno, como forma de se obter um retrato fiel da prática. Na contracapa dos cadernos encontrava-se a seguinte orientação:

Caro(a) aluno(a),

Este caderno servirá para acompanhamento de todas as aulas dadas em sua turma. Quando você for o escriba do dia, zele por ele do início ao fim do período e devolva-o no final da 6a aula ao(à) professor(a). Caso seja aula vaga, entregue-o à inspetora de alunos. Instruções para registros:

Coloque a data;

Identifique a disciplina (português, geografia, matemática, etc.) de cada aula antes de tomar nota das lições; Registre todas as atividades dadas, tais como leituras, cópias de textos, explicações, filmes, exercícios, etc.

Bom trabalho!!

A direção.

6 A RME/SP adotava, em 2010, a nomenclatura série para designar as etapas escolares correspondentes ao Ensino Fundamental de oito anos. Posteriormente, houve adequação para o Ensino Fundamental de nove anos, quando as turmas passaram a ser designadas como ano. 
Como a coordenadora à época não se encontra mais na escola, o que temos são indícios do objetivo que ela tinha com esses documentos. Sabemos que hoje essa é uma prática que poucos professores utilizam nessa escola; a maioria prefere realizar os registros em diários de classe e no SGP7.

Sendo assim, realizamos uma análise documental e duas entrevistas com as professoras responsáveis pelas turmas de 2a e 4ํㅡ séries de 2010 citadas nos diários de bordo, com o intuito de analisar a materialização da presença das avaliações externas no cotidiano escolar a partir dos registros nesses diários.

As entrevistas foram realizadas no mês de junho de 2015 nas dependências da própria escola. Primeiro apresentamos o perfil das entrevistadas. As duas professoras possuem formação em Pedagogia. Além disso, a profa. Joana ${ }^{8}$ tem pós-graduação em Psicopedagogia e a profa. Tereza é formada também em Gestão Escolar e Docência no Ensino Superior.

A entrevista foi composta de apenas um bloco com 25 questões. 0 tempo médio de atuação das professoras na educação é de 20 anos, e o tempo médio de atuação na escola é de seis anos.

SGP - Sistema de Gestão Pedagógica adotado pela RME/SP em 2014, implantado com o objetivo de informatizar, entre outros aspectos, os registros acadêmicos.

8 Os nomes das professoras são fictícios para preservar sua identidade. 
Perfil e ATUAÇÃO PROFISSIONAL

Com o objetivo de retratar aspectos da identidade profissional das professoras entrevistadas, elaboramos o Quadro 1, que mostra a formação, os anos na carreira docente e o tempo de atuação na escola.

Quadro 1 - Perfil dos sujeitos da pesquisa

\begin{tabular}{|c|c|c|}
\hline Estratos & \multicolumn{2}{|c|}{ Perfil dos sujeitos } \\
\hline Professores & Profa Tereza & Profa Joana \\
\hline Formação & Pedagogia & Pedagogia \\
\hline Tempo de carreira & 22 anos & 23 anos \\
\hline Pós-graduação & $\begin{array}{c}\text { Docência no Ensino } \\
\text { Superior e Gestão } \\
\text { Escolar }\end{array}$ & Psicopedagogia \\
\hline $\begin{array}{c}\text { Tempo de atuação } \\
\text { por dependência } \\
\text { administrativa }\end{array}$ & $\begin{array}{c}3 \text { anos na SEE/SP } \\
19 \text { anos na SME/SP }\end{array}$ & $\begin{array}{c}13 \text { anos escola } \\
\text { particular } \\
1 \text { ano na SEE/SP } \\
23 \text { anos na SME/SP }\end{array}$ \\
\hline $\begin{array}{c}\text { Tempo de atuação } \\
\text { na unidade escolar } \\
\text { pesquisada }\end{array}$ & 5 anos & 7 anos \\
\hline
\end{tabular}

Fonte: Elaborado pela autora.

Em relação à formação de professores, é oportuna a observação de Vieira e Fernandes (2011), de que se trata de um processo contínuo, iniciando-se na graduação e estendendo-se por toda a sua trajetória profissional. Embora ambas as professoras tenham pós-graduação, tal formação não foi suficiente para prepará-las para a função de avaliadoras, tampouco lhes deu condições de interpretar ou de utilizar os dados resultantes das avaliações externas. Segundo Schmidt (1999, p. 18), a formação dos professores é uma das causas fundamentais que influenciam a qualidade do ensino:

[...] no cotidiano das escolas públicas, o processo de ensino/aprendizagem, que é objeto de estudo da didática, vem sofrendo as consequências dessas políticas, o que repercute na qualidade do ensino. As mazelas deste cotidiano recaem, principalmente, na figura do professor, que é considerado como um dos responsáveis pela má qualidade do ensino, sem que se considerem as condições de sua formação e as relações sociais estabelecidas. 
Desde os anos 1980 a formação docente tem sido tema recorrente no debate educacional. Apesar da profusão de trabalhos abordando esse assunto, concordamos com Moreira (2008, p. 81) quando observa que não houve mudanças relevantes:

[...] apesar do avanço teórico e das propostas inovadoras implementadas, as configurações básicas do sistema e formação de professores não se têm alterado significativamente. Tal situação inevitavelmente frustra os que esperam de uma formação de docentes renovada as indispensáveis contribuições para a construção de uma escola de qualidade em nosso país, ainda que difiram os sentidos e as intenções atribuídos a essa qualidade.

\section{RESULTADOS PARCIAIS}

Concebendo os diários como instrumentos de registro e não apenas da rotina da sala de aula, mas também revelador das concepções de professores, Zabalza (2004, p. 13) assegura que os diários são “[...] documentos em que professores e professoras anotam suas impressões sobre o que vai acontecendo em suas aulas”. Partindo desse pressuposto, é vasta a presença das avaliações externas nos diários analisados, sendo a maior parte desses registros de natureza jornalística e alguns de conteúdo etnográfico, conforme diferencia Holly (1989, p. 61-81, apud ZABALZA, 2004, p. 15):

- Jornalística: de natureza fundamentalmente descritiva e seguindo as características próprias do jornalismo;

- Etnográfica: o conteúdo e o sentido do narrado (mesmo permanecendo nos limites das descrições) levam em consideração os contextos físico, social e cultural em que ocorrem os fatos narrados.

Nos registros, observa-se que a escola se preocupava com a realização de simulados para preparação dos alunos:

Atividade do dia: Revisão de Contos. Novamente feita a leitura dos contos. [...] todos vocês, a festa no céu e a princesinha [...] com o objetivo de preparar o aluno para a Prova São Paulo (registro de aluno - diário de bordo). 
Verificou-se ainda a preocupação em fazer uso dessas avaliações. Vários registros demonstram a tentativa de tornar úteis as informações referentes a elas:

9 Fizemos as questões da Prova da Cidade como correção da $1^{a}$ à $10^{a}$, conversando sobre cada questão (registro de professor - diário de bordo).

A correção da Prova da Cidade foi produtiva, pois os alunos se manifestaram em nível de acertos e erros. Fizeram a prova no caderno (registro de professor - diário de bordo).

Os registros demonstram uma tentativa de tornar as avaliações externas parte da rotina da sala de aula, muito embora não haja pleno entendimento sobre como fazê-lo. Percebe-se, pelos registros e pela fala das professoras, que falta conhecimento técnico, propriamente dito, sobre as informações que uma avaliação externa pode oferecer e, consequentemente, os usos que podem ser feitos. A utilização dos dados referentes ao desempenho dos alunos se resumia a correções, reproduzindo a rotina de discussão sobre erros e acertos, que é pertinente, porém insuficiente:

[...] Demos continuidade à correção da Prova da Cidade. Mais algumas questões foram estudadas; demos início também à correção da prova de matemática. Os alunos, em sua maioria, apresentam algumas dificuldades, sendo assim um pouco mais demorada esta correção (registro de professor - diário de bordo).

Ao entrevistarmos as professoras, percebemos que o objetivo dos diários era o acompanhamento das atividades das turmas. Nota-se que muitos dos registros foram realizados como uma demanda momentânea, sem reflexão sobre a ação, especialmente quando esses registros eram feitos pela professora, conforme a profä. Tereza:

[...] era para fazer com que acompanhasse o conteúdo, para que não fosse feito o semanário. Era para acompanhar a sequência de conteúdos.

Por outro lado, a percepção da profạ. Joana, cujos registros eram realizados pelos alunos, era menos burocrática e mais pedagógica, como observamos na entrevista:

[...] pelo que eu me lembro e pelo que coloquei na minha sala, era a questão do aluno reconhecendo e registrando suas próprias atitudes. É... alguma coisa que ele quisesse estar registrando e ter autonomia para registrar, para fazer o registro. Para ele era superdiferente,

registrando.

9 Criada em 2009, a Prova da Cidade foi uma avaliação diagnóstica, produzida por professores da RME/SP, cuja aplicação e correção eram realizadas pelas próprias escolas e que vigorou até 2012. Fonte: 〈http://www.portalsme.prefeitura.sp.gov.br/Projetos/ nucleo/AnonimoSistema/MenuTexto.aspx?MenuID=47\&MenuIDAberto=24 . 
Com o tempo, porém, a prática de registro do aluno mudou para registro do professor, mesmo para a profa . Joana, que, depois de um tempo, achou melhor fazer os próprios registros, pois os alunos enfrentavam dificuldades para fazê-lo:

[...] eu aceitei como um desafio, aceitei como uma coisa nova para mim, mas quando eu comecei a colocar em prática, eu vi que o aluno perdia o tempo de fazer o registro.

Os simulados eram aplicados na véspera da PSP. Questionadas sobre como preparavam os simulados e qual o objetivo, as lacunas formativas em avaliação ficaram evidentes, uma vez que eram os próprios professores que desenvolviam os instrumentos, sem preparo para tal e com o objetivo principal de preparar para a prova:

[...] o objetivo era preparar os alunos para a prova e também para a gente ver quais seriam as dificuldades que eles iam ter para realizar a prova. Nos simulados, a gente já percebia algumas coisas e já trabalhava melhor naquele sentido.

[...] alguns professores traziam modelos de provas de outras escolas e aí a gente usava e tirava algumas questões que a gente achava interessante (prof ${ }^{a}$. Tereza).

As correções da Prova da Cidade, outro ponto bastante citado nos diários de bordo, revelaram-se infrutíferas e repetitivas, acumulando-se junto ao trabalho docente sem fins pedagógicos claros. Perguntamos às professoras qual era o objetivo das correções dessa avaliação e verificamos que se tratava de uma atividade limitada à verificação de erros e acertos dos alunos:

Não sei qual era o objetivo. A gente corrigia para dar um retorno para o aluno, só isso. E parava por aí. Ninguém vinha perguntar se a gente tinha feito as correções ou não e também eu fazia por mim, porque eu queria dar um retorno para os meus alunos. Falar assim: - Ó, você acertou aqui...e errou ali... (prof ${ }^{a}$. Joana).

O desconhecimento sobre as características da Prova São Paulo também chamou a atenção nas falas das entrevistadas, uma vez que se tratava de uma iniciativa municipal. Embora a escola se mobilizasse para realizar simulados como preparatório para essa avaliação, alguns professores não sabiam sequer que tal avaliação divulgava seus resultados por aluno, o que a diferenciava de outras avaliações a que a Rede era submetida e dava condições aos professores de um acompanhamento individual aliado ao trabalho realizado em sala de aula. Ambas as professoras, quando questionadas sobre o uso dos resultados, mostraram-se surpresas com tal informação, 
Nossa, estou sabendo disso agora, nem imaginava. Se a gente soubesse disso ia ser bom. Porque a gente ia ter uma ideia de como estava o aluno e de como estava a sala e daí poderia pensar em alguma coisa. Então... eu nem imaginava isso e na minha opinião muita gente não sabe (que a PSP divulgava para a rede os resultados por aluno) e isso é importante a gente saber para a gente trabalhar melhor, ir atrás do erro do aluno e trabalhar [...] (prof ${ }^{a}$. Joana).

Desconhecem também algumas informações essenciais para compreender os resultados de uma avaliação externa, como, por exemplo, o que são descritores e distratores, o que é uma matriz de referência e como interpretar uma escala de proficiência. A falta de conhecimento sobre a estrutura de uma avaliação externa compromete a interpretação dos resultados, contribui para o afastamento dos professores e dificulta, portanto, a incorporação de tais avaliações na reorientação de suas práticas.

A escassa e, às vezes, ausente formação em avaliação explica, em tese, a resistência dos professores em relação às avaliações externas. Quando abordamos a profa. Joana para convidá-la a participar da pesquisa concedendonos uma entrevista, ela se mostrou reticente quanto ao assunto, dizendo-nos que era contra as avaliações externas. No entanto, sentiu-se à vontade para participar da entrevista proposta. No final da entrevista, quando perguntamos: “Em sua opinião, é necessário que haja avaliações externas?”, ela nos disse:

Bom, se é assim do jeito que você me explicou é bem legal, só que a gente não tem essas informações que você me passou agora, então fica difícil. Antes eu até não gostava, mas agora vou prestar mais atenção nessas provas (prof ${ }^{a}$. Joana).

O que se percebe é que há muita especulação e pouca discussão técnica sobre o tema, contribuindo para uma série de equívocos acerca das avaliações externas, o que ficou evidente nas falas das respondentes. Chama a atenção o fato de estarmos na maior Rede municipal de ensino do país, cuja secretaria reserva um departamento que atua na formação, inclusive de professores, a saber:

A Diretoria de Orientação Técnica Pedagógica é de atuação regional e vinculada à Diretoria de Orientação Técnica - SME, cuja atuação é central, ou seja, atende toda a cidade. Compõe a DOT-P, o Centro de Formação e Acompanhamento à Inclusão- CEFAI.

Para a Gestão 2013-2016, DOT-SME, definiu como eixos de trabalho para atuação conjunta com DOT-P: Currículo, Formação e Avaliação. [...] para este ano definimos como pressupostos estruturantes para a atuação da DOT-P:

[...] Valorização da formação em pequenos grupos, setores, por escola, em horários coletivos, enfim, investir na proximidade do formador no cotidiano educacional como espaço privilegiado do conhecimento e produção de saberes (Portal SME/SP, grifos do autor). 
Não refutamos que a SME/SP tenha efetivas ações formativas para os professores, coordenadores e diretores, mas percebemos uma lacuna em tais ações com relação às especificidades da avaliação, o que nos surpreende, porque a avaliação está intrinsecamente ligada à ideia de qualidade da educação. Como assevera Castro (2013), a avaliação pode nos mostrar as reais condições de desempenho dos alunos e, consequentemente, dispor de dados para análise do funcionamento das unidades escolares e suas possíveis imperfeições. Observa-se que os professores da RME/SP, embora estejam diante de uma intensa presença de avaliações externas, vivem o que Alavarse (2013) chamou de "paradoxo docente”, uma vez que são avaliadores profissionais, mas não recebem formação para tal atividade.

A própria prática de avaliação interna não recebe atenção devida nos cursos de licenciatura, como demonstram vários estudos (GATTI, 2011; GATTI; NUNES, 2009; GONÇALVES; MAIMONE, 2010; TAVARES, 2008), revelando que o professor não aprende a avaliar na formação inicial e, mesmo nos programas de formação continuada, a preparação docente para a avaliação dos alunos é pouco abordada, tratada de forma abstrata.

Ao mesmo tempo que é escassa a formação em avaliação, são implementadas novas iniciativas na área pela RME/SP. O caso mais recente é a Prova Mais Educação, instituída por meio da Portaria n. 3.611, de 29 de maio de 2015. De acordo com o documento oficial, esta será uma

\section{[...] avaliação censitária, de larga escala, a ser aplicada bimestralmente por todas as Unidades Educacionais que mantêm o Ensino Fundamental da Rede Municipal de Ensino, a partir do $3^{\circ}$ ano do Ciclo de Alfabetização e em todos os anos dos Ciclos Interdisciplinar e Autoral (SÃO PAULO, 2015, Art. $1^{0}, \S$ I).}

A imposição de mais uma avaliação é um retrocesso na medida em que não privilegia o diálogo, tampouco a formação em avaliação, o que limita a compreensão e inibe a adesão dos profissionais da educação, especialmente professores. Conforme afiança Alavarse (2015), “[...] essa miríade de provas vai ceifar tempo de ensino para consumi-lo na aplicação e processamento de respostas e interpretação, sem garantias de que isso efetivamente melhore os processos de avaliação e os usos pedagógicos".

Procuramos, neste texto, por meio da análise de diários de bordo e entrevistas, apreender a real influência das avaliações externas no currículo da escola pesquisada procurando, ao mesmo tempo, evidenciar as limitações e/ou potencialidades desses exames. Pudemos constatar a forte presença 
dessas avaliações no cotidiano da unidade escolar pesquisada, na forma de simulados da PSP e correções da Prova da Cidade. No entanto, não nos parece uma presença como forma de controle, como critica Freitas (2002). 0 que percebemos foi uma tentativa da escola de se apropriar dos resultados e preparar os alunos, numa visão ingênua de treino sobre conteúdos às vésperas da prova. A adoção de simulados pode ser positiva a depender do objetivo a que se destina. Conforme salienta Blasis (2014, p. 13), eles podem se tornar interessantes “[...] quando são utilizados como diagnóstico para 0 planejamento de intervenções, visando à promoção de aprendizagens”. 0 que as entrevistas revelaram, entretanto, foi sua adoção como treino, para verificação se os alunos estão preparados para as avaliações externas.

Observamos, ainda, um distanciamento entre a instância que elabora tais avaliações e aquelas que de fato poderão consumir seus dados. A estes últimos, faltam conhecimentos, desde os mais básicos, como a possibilidade de acompanhamento da trajetória dos alunos, caso da PSP, até questões mais técnicas, mas fundamentais para a interpretação pedagógica e uso dos resultados como, por exemplo, a composição de um item, a função dos distratores e dos descritores, o conhecimento de uma escala de proficiência e até o papel de uma Matriz de Referência, pois ambas as entrevistadas assumiram desconhecer, inclusive, essas terminologias. Essa lacuna formativa ficou evidente ao perguntarmos às professoras: você considera que os professores têm formação para interpretar resultados das avaliações externas? Ao que foram enfáticas em responder: "De jeito nenhum” (profạ . Joana) e “Não, nós não temos” (profạ. Tereza).

Corroborando a tese acerca da necessidade de formação no campo da avaliação e do potencial das avaliações externas para o trabalho docente e para o avanço da aprendizagem dos alunos, consideramos o estudo de Alavarse e Machado (2013) que revela incongruências existentes entre os resultados das avaliações em larga escala e a avaliação realizada pelos professores. Ao cotejar os resultados das avaliações interna e externa, no caso, a PSP, os pesquisadores observaram diferenças entre resultados que, em alguns casos, significou a reprovação de alunos, evidenciando a necessidade de problematização das avaliações em larga escala, e também das práticas avaliativas dos professores. Ressalta-se, nesse contexto, o caráter facilitador de avaliações como a PSP. Diante das características já citadas, trata-se de um desenho mais apropriado à utilização dos dados, seja pelo desenvolvimento, que contou com ampla participação da comunidade escolar, seja pela forma de divulgação de resultados. 
Apoiamo-nos nas considerações de $\operatorname{Nevo}(1998,2006)$ ao lembrar que a formação inicial do professor não é na área de avaliação, sendo esta apenas uma parte da descrição de suas funções, e, portanto, assim como os alunos não ficam motivados a usar o que aprendem por meio de uma educação bancária, esses profissionais não ficam motivados a usar uma avaliação que seja apresentada a eles por meio de um discurso coercivo de uma só via. O autor propõe uma abordagem “[...] baseada na escola, aproveitando as concepções atuais de avaliação educacional, e determinando orientações práticas para essa aplicação” (NEVO, 1998, p. 90). Com base em trabalho realizado em várias escolas, sugere ainda que um "discurso de mudança” seja necessário na avaliação educacional, “[...] para fazê-la passar de um discurso de descrição e de julgamento para um discurso de diálogo" (NEVO, 1998, p. 90).

Machado (2013, p. 54), ao apresentar o que seria uma mudança paradigmática na avaliação, admite que estamos diante de uma "cisão revolucionária" com os modelos anteriores ${ }^{10}$ em uma fase da avaliação em que:

\section{[...] a ignorância dos vários intervenientes e as tentativas deliberadas de diminuição do poder, nomeadamente através do controlo dos resultados da avaliação, é substituída pela exigência de atribuir mais poder (empowerment) aos sujeitos, negociando com os interessados (stakeholders), partilhando a informação e colaborando na construção dos sentidos da avaliação.}

Percebe-se, por meio dos trabalhos analisados, para além da urgência do uso dialógico das avaliações internas e externas, que há a necessidade de mudança na concepção que temos dos avaliados, sendo preciso admitir que há lacunas formativas e envolver os docentes em uma ação de meta-avaliação direcionada tanto aos instrumentos internos quanto externos, com o objetivo de fortalecer o uso das avaliações externas. É preciso considerar o que Guba e Lincoln (1989 apud Machado, 2013) asseveram sobre a mudança no papel do avaliador, de um mero técnico a "um intérprete e um agente de mudança" e também sobre o papel dos avaliados, que passam de indivíduos "medidos e controlados", característica da primeira geração, até "agentes ativos e participativos, colaborando, discutindo e negociando" (GUBA; LINCOLN, 1989 apud MACHADO, 2013, p. 50).

Diante desse cenário, torna-se fundamental repensarmos o papel da avaliação na escolarização de massas. Qual é o objetivo da avaliação interna

10 Em Machado (2013), o autor expõe com clareza quatro gerações de avaliação, abordando em cada uma as mudanças em relação ao objetivo da avaliação, o papel do avaliador e 0 papel dos avaliados. 
ou da aprendizagem? Como garantir sua função formativa quando se pensa no espaço que ocupa na formação inicial de professores? Como utilizar os indicadores externos a favor da aprendizagem? Na perspectiva de Mons e Crahay (2011), a avaliação externa ou padronizada, mais que uma ferramenta de publicidade de ações políticas, deve ser utilizada como um instrumento de reconfiguração da ação pública em educação, que possa transformar as práticas pedagógicas e fazer evoluir as relações de poder entre atores tradicionais do setor, a saber, o Estado, os profissionais da educação, como professores e equipes de gestão, e, ainda, a comunidade local e os pais.

Cabe reforçar o que já foi indicado no texto: é crucial a apropriação aprofundada, pelos professores, dos objetivos e resultados das avaliações externas, para que possam ser incorporadas ao desenvolvimento do seu trabalho, como salientam Alavarse e Machado (2013). Não sabemos se os cursos de formação garantirão o desenvolvimento de competências profissionais que a avaliação externa requer, mas acreditamos que, no limite, poderão estimular a reflexão dos educadores a fim de interagirem com mais proximidade e profundidade em relação a concepções em torno das avaliações externas, potencializando e/ou (re)organizando o conhecimento dos diferentes atores educacionais.

Sem esses conhecimentos, a interpretação e, consequentemente, o uso dos resultados das avaliações externas ficam comprometidos, o que certamente impacta a qualidade da educação de milhões de crianças e jovens brasileiros. 


\section{External assessments and teaching: what teachers' records say?}

Abstract: The dissemination of external assessments as a defining feature of educational policies has consolidated as a decision-making tool for public education systems. In this article, we present findings of a doctoral research we conducted at a school of the São Paulo Municipal Education System (RME/ SP) which dealt with the influences of external evaluations on teachers' conceptions. We analyzed teachers' records in class diaries in order to see how these assessments reverberate in school. In addition to the heavy presence of these municipal assessments in the records in the form of practice tests for the Prova São Paulo [São Paulo Test], corrections of the Prova da Cidade [City Test] and talking circles, we found a lack of knowledge of the characteristics of these exams by the teachers, which hinders the pedagogical interpretation and, therefore, the use of their results by the teachers.

Keywords: External assessments. Use of results. Class diaries. Prova São Paulo. 


\section{Evaluaciones externas y trabajo docente: ¿qué dicen los registros de los profesores?}

Resumen: La propagación de las evaluaciones externas como rasgo característico de las políticas educativas se ha consolidado como un instrumento de toma de decisiones de redes públicas de enseñanza. En este artículo, presentamos resultados de una investigación de doctorado realizada en una escuela de la Red Municipal de Enseñanza de São Paulo (RME/SP) que versa sobre las influencias de las evaluaciones externas en las concepciones de los profesores. Se analizaron registros de profesores en diarios de a bordo con vistas a comprender cómo estas evaluaciones se reflejan en la escuela. Además de la fuerte presencia de las evaluaciones municipales en los registros bajo la forma de simulaciones del Examen São Paulo, correcciones del Examen de la Ciudad y ruedas de conversación, constatamos la falta de conocimientos sobre las características de estos exámenes por parte de los profesores, lo que dificulta la interpretación pedagógica y, por consiguiente, el uso de los resultados por su parte.

Palabras clave: Evaluaciones externas. Uso de resultados. Diarios de a bordo. Examen São Paulo. 


\section{REFERÊNCIAS}

AFONSO, A. J. Políticas educativas e avaliação educacional. Minho: Universidade do Minho, 1998.

ALAVARSE, O. M. Desafios da avaliação educacional: ensino e aprendizagem como objetos de avaliação para a igualdade de resultados. Cadernos Cenpec, São Paulo, v. 3, n. 1, p. 135-153, jun. 2013.

. Excesso de provas tira tempo de ensino e não garante melhorias.

O Estado de S. Paulo, Estadão Educação. Disponível em: 〈http://educacao. estadao.com.br/noticias/geral, analise-excesso-de-provas-tira-tempo-deensino-e-nao-garante-melhorias,1706934>. Acesso em: 17 jul. 2015.

; MACHADO, C. Avaliações externas e formação de professores: desafios para uma educação de qualidade. In: CONGRESSO INTERNACIONAL DE AVALIAÇÃO, 3.; CONGRESSO INTERNACIONAL DE EDUCAÇÃO, 8., 2013, Gramado. Anais... Gramado, 2013.

ARELARO, L. R. G. Direitos sociais e política educacional: alguns ainda são mais iguais que outros. In: SILVA, S.; VIZIM, M. (org.). Políticas públicas: educação, tecnologias e pessoas com deficiências. Campinas, SP: Mercado de Letras: Associação de Leitura do Brasil (ALB), 2003. (Leituras no Brasil). p. 13-36.

BARROSO, J. A regulação da educação. In: Políticas educativas e organização escolar. Lisboa: Universidade Aberta, 2005. p. 63-91.

BLASIS, E. de (Org.). Avaliação educacional: os desafios da sala de aula e a promoção da aprendizagem. Coordenação Eloisa de Blasis e Patricia Mota Guedes. São Paulo: Cenpec, Fundação Itaú Social, 2014.

CASTRO, A. M. Um estudo sobre o Saresp e a repercussão dos seus resultados em uma escola da Zona Leste da cidade de São Paulo. 2013. 135 f. Dissertação (Mestrado em Políticas Sociais)-Universidade Cruzeiro do Sul, São Paulo, 2013.

CASTRO, M. H. G. Sistemas nacionais de avaliação e de informações educacionais. São Paulo em Perspectiva, v. 14, n. 1, p. 121-128, 2000.

. O desafio da qualidade. In: ITUASSU, A.; ALMEIDA, R. de (Org.). 0 Brasil tem jeito? Rio de Janeiro: Jorge Zahar, 2007. v. 2, p. 35-72.

CHARTIER, A. M. En quoi instruire est um métier. Esprit, n. 12, p. 55-77, 1991. 
CHIZZOTTI, A. Pesquisa em ciências humanas e sociais. São Paulo: Cortez, 2005.

DIAS SOBRINHO, J. Campo e caminhos da avaliação: a avaliação da educação superior no Brasil. In: FREITAS, Luiz C. (Org.). Avaliação: construindo o campo e a crítica. Florianópolis: Insular, 2002.

DÍAZ BARRIGA, Á. Uma polêmica em relação ao exame. Tradução Maria Teresa Esteban. In: ESTEBAN, M. T. (Org.). Avaliação: uma prática em busca de novos sentidos. 5. ed. Petrópolis: DP et alii, 2008. (Pedagogias em Ação). p. 43-66. [Original 1990].

ESTEBAN, M. T. A negação do direito à diferença no cotidiano escolar. Avaliação, Campinas, Sorocaba, v. 19, n. 2, p. 463-486, jul. 2014.

FREITAS, L. C. Avaliação: construindo o campo e a crítica. Florianópolis: Insular, 2002.

GATTI, B. A. Formação docente, pouco preparo. UOL Educação, 2011. Disponivel em: < http://revistaeducacao.uol.com.br/formacao-docente/174/ pouco-preparo-236326-1.asp> Acesso em: 10 fev. 2014.

; NUNES, M. M. R. (Org.). Formação de professores para o ensino fundamental: estudo de currículos das licenciaturas em pedagogia, língua portuguesa, matemática e ciências biológicas. São Paulo: Fundação Carlos Chagas, mar. 2009. 158 p. (Textos FCC, v. 29).

GIL, A. C. Métodos e técnicas de pesquisa social. São Paulo: Atlas, 1999.

GONÇALVES, G. S. de Q.; MAIMONE, E. H. Formam-se professores avaliadores? In: DONATONI, A. R. (Org.). Avaliação escolar e formação de professores. 2. ed. Campinas: Alínea, 2010. p. 53-72.

LUDKE, M.; ANDRÉ, M. E. D. A. Pesquisa em educação: abordagens qualitativas. São Paulo: EPU, 1986.

MACHADO, E. A. Avaliar é ser sujeito ou sujeitar-se? Elementos para uma genealogia da avaliação. Portugal: Edições Pedago, 2013.

MADAUS, G. F. The influence of testing on the curriculum. In: TANNER, L. N. (Ed.). Critical issues in curriculum: Eighty-seventh Yearbook of the National Society for the Study of Education. Part I. Chicago: University of Chicago Press, 1988. p. 83-121. 
MONS, N.; CRAHAY, M. L'évaluation des performances scolaires des élèves: un instrument d'évaluation des politiques éducatives? In: FELOUZIS, G.; HANHART, S. (Ed.). Gouverner l'éducation par les nombres?: usages, débats et controverses. Bruxelles: De Boeck, 2011. (Raisons Éducatives). p. 77-98.

MOREIRA, A. F. B. (Org.). Currículo: políticas e práticas. 10. ed. Campinas: Papirus, 2008.

NEVO, D. Avaliação por diálogos: uma contribuição possível para o aprimoramento escolar. In: TIANA, A. (Coord.). Anais do Seminário Internacional de Avaliação Educacional, 1 a 3 de dezembro de 1997. Tradução John Stephen Morris. Brasília: Instituto Nacional de Estudos e Pesquisas Educacionais, 1998. p. 89-97.

Evaluation in education. In: SHAW, I. F.; GREENE, J. C.; MARK, M. M. (Ed.). Handbook of evaluation: policies, programs and practices. London: Sage, 2006. p. 441-460.

PORLÁN, R.; MARTÍN, J. El diario del professor: um recurso para la investigación en el aula. Sevilla: Diada, 1997.

SANTOS, M. da G. P. dos; FÉLIX, I. P. F. A avaliação externa e a identidade docente. In: CONGRESSO NACIONAL DE LINGUÍSTICA E FILOLOGIA, 18., 2014, Rio de Janeiro. Cadernos do CNFL, v. XVIII, n. 7 - Fonética, Fonologia, Ortografia e Política Linguística e de Ensino. Rio de Janeiro: Cifefil, 2014. p. 276-290.

SÃO PAULO (Município). Secretaria Municipal de Educação. Decreto n. 47. 683, de 14 de setembro de 2006. Regulamenta a Lei 14.063, de 14 de outubro de 2005, que institui o Sistema de Avaliação de Aproveitamento Escolar dos Alunos da Rede Municipal de Ensino de São Paulo, sob responsabilidade da Secretaria Municipal de Educação. Diário Oficial da Cidade de São Paulo, São Paulo, 15 set. 2006, p. 1.

Secretaria Municipal de Educação. Portaria n. 3.611, de 29 de maio de 2015. Dispõe sobre a instituição da Prova Mais Educação. Diário Oficial da Cidade de São Paulo, São Paulo, 30 maio 2015, p. 16.

SCHMIDT, L. L. A política de formação de professores no Brasil e suas implicações na prática pedagógica. Ponto de Vista, v. 1, n. 1, p.18-29, jul./dez. 1999. 
SOUSA, S. M. Z. L. et al. Avaliação educacional e gestão: iniciativas no âmbito do Município e do Estado de São Paulo. In: REUNIÃO ANUAL DA ANPED, 23: GT5: Estado e Política Educacional: Política, Gestão e Financiamento da Educação, 2000, Caxambu. Anais... São Paulo: Anped, 2000. p. 429-435.

; OLIVEIRA, R. P. de. Sistemas estaduais de avaliação: uso dos resultados, implicações e tendências. Cadernos de Pesquisa, São Paulo, v. 40, n. 141, p. 793-822, set./dez. 2010.

STECHER, B. M. Consequences of large-scale, high-stakes testing on school and classroom practice. In: HAMILTON, L.; STECHER, B. M.; KLEIN, St. P. (Ed.). Making sense of test-based accountability in education. Santa Monica, CA: Rand, 2002. p. 79-100.

TAVARES, C. Z. Formação em avaliação: a formação de docentes no enfrentamento de um processo de avaliação a serviço da aprendizagem. Tese (Doutorado em Educação - Currículo)-Pontifícia Universidade Católica de São Paulo, São Paulo, 2008.

THIOLLENT, M. Metodologia da pesquisa-ação. São Paulo: Cortez, Autores Associados, 1986.

VIEIRA, R. A.; FERNANDES, C. P. Avaliações externas em foco: percepções e efeitos para o trabalho docente. Educação em Perspectiva, Viçosa, v. 2, n. 1, p. 119-132, jan./jun. 2011.

ZABALZA, M. A. Diários de aula: um instrumento de pesquisa e desenvolvimento profissional. Tradução Ernani Rosa. Porto Alegre: Artmed, 2004.

\section{SOBRE A AUTORA}

Valéria Aparecida de Souza Siqueira é doutora em Educação pela Faculdade de Educação da Universidade de São Paulo (Feusp). Atualmente é docente do curso de Pedagogia da Universidade Paulista (Unip). E-mail: valeriasiqueiral8@gmail.com.

Recebido em: junho de 2018

Aprovado em: agosto de 2018 